\title{
Hydro Pump Storage Energy Units in Crete's Power System
}

\author{
Emmanuel S. Karapidakis ${ }^{1}$
}

\begin{abstract}
Large scale integrating of wind power generation into a grid may raise serious stability issues. In this case energy storage systems seem to be suitable for balancing power and energy between the inconstant wind parks generation and the grid. In this paper, the impact of high wind power penetration on the dynamic performance and stability of power systems is investigated. More precisely, the focus of this study is to assess the operation of pump storage systems in the autonomous power system of a large island such as Crete. Results of this study show that it is possible to achieve a large wind power penetration without significant dynamic security problems, if wind energy pump storage units are in operation.
\end{abstract}

\section{Keywords}

Renewable energy sources, island power systems, hydro pump storage units.

\section{Acknowledgement}

This research has been co-financed by the European Union (European Social Fund - ESF) and Greek national funds through the Operational Program "Education and Lifelong Learning" of the National Strategic Reference Framework (NSRF) - Research Funding Program: ARCHIMEDES III. Investing in knowledge society through the European Social Fund.

\footnotetext{
${ }^{1}$ School of Applied Science,

Technological Educational Institute of Crete

Estavromenos Campus, Heraklio, Greece

(e-mail: karapidakis@ @staff.teicrete.gr)
}

\section{Introduction}

In island systems, dynamic performance and stability is a crucial issue and a major concern, since mismatches in generation and load and/or unstable system control might lead to frequent system failures, $[1,2]$. Although, renewable and especially wind parks exploitation appear particularly attractive, they present an unpredictable character and problems may appear when integrating it in a large scale, [3-5]. Moreover, the integration of a substantial amount of wind power in autonomous power systems needs careful consideration, so as to maintain a high degree of reliability and security of the system operation.

The main problems identified concern operational scheduling (mainly unit commitment) due to high production forecasting uncertainties, as well as steady state and dynamic operating problems. These problems may considerably limit the amount of wind generation that can be connected to the island systems, increasing the complexity of their operation. Thus, next to the more common angle and voltage stability concerns, frequency stability must be ensured [6]. This depends on the ability of the system to restore balance between generation and load following a severe system upset with minimum loss of load. Energy storage could eliminate these problems. Especially, pumped storage units can contribute, as the extra energy provided by the wind turbine is used to pump water from an inferior basin into a superior one, which is then released when more power and/or energy is needed $[7,8]$. Pumped storage presents many advantages like long time storage period without losses, fast response in load demand, high storage capacity, and good efficiency at high power level, while it is the only successfully

This is an Open Access article distributed in accordance with the Creative Commons Attribution Non Commercial (CC-BY-NC-ND 4.0) license, which permits others to copy or share the article, provided original work is properly cited and that this is not done for commercial purposes. Users may not remix, transform, or build upon the material and may not distribute the modified material (http://creativecommons.org/licenses/by-nc/4.0/) 
implemented storage method for high power levels.

In this case, dynamic simulation studies must be among the first steps in determining the level of wind power penetration in isolated power systems, [9]. Thus analytical studies are required in order to derive security rules and guidelines for the optimal operation of these complex systems, [10]. Studies on the dynamic stability of the isolated power system are necessary, monitoring voltage and frequency calculations under several abnormal operating conditions, e.g. start-up or sudden disconnection of wind generation, wind fluctuations, short circuits on the network etc, hydro units and pumps operation.

Furthermore, several obstacles and technical restrictions are evident in island's the energy sector, such as higher total costs, fluctuations in the price and insecurity of supply. However, these disadvantages can be outweighed by inherent advantages, especially by utilization of renewable energy technologies, thanks to their relative high wind and sun exposure [3]. This potential should be better exploited in order to investigate the operation and planning limitations and estimate the possible solutions $[4,5,11]$.

The new operating and planning policies imposed by the current demands for increased efficiency and economy, dictate the need to operate the power system in a more stressed way [6]. More precisely, several previous studies have analyzed the feasibility, and benefits of high percentage electricity supply from RES technologies in Crete [7-9].

This paper analyses the possibilities of high percentage electricity supply from RES technologies in Crete taking into account operation of hydro pump energy storage units.

\section{Power System Presentation}

Crete's electricity generation system is based mainly on three (3) oil-fired thermal power plants with more than 25 generators and approximately $700 \mathrm{MW}$ power capacity in total. Additionally, there are 25 wind parks installed with nominal power of approximately 167MW (215MW in near future) across the island. These WPs are connected to the grid through $\mathrm{MV} / \mathrm{HV}$ substations of $20 \mathrm{kV} / 150 \mathrm{kV}$. Additionally, 1200 small PV plants of $80 \mathrm{~kW}$ nominal power each are already installed or are about to be installed.

The steam and diesel power units mainly supply the base-load. The Gas turbines normally supply the daily peak load or the load that cannot be supplied by the other units in outage conditions. These units have a high running cost that increases significantly the average cost of the electricity being supplied.

As in most autonomous systems, Crete's power system has considerable load demand variations, [12-14]. In particular, the following Fig. 1 shows the recorded minimum and maximum loads per day in 2014. Load factor in this case is about $26 \%$, revealing the reasonable need for energy storage systems, such as reversible hydroelectric projects, which will contribute greatly to the normalization of demand, and the optimal management and further integration of RES.

Fig. 1 Max \& Min of daily load demand

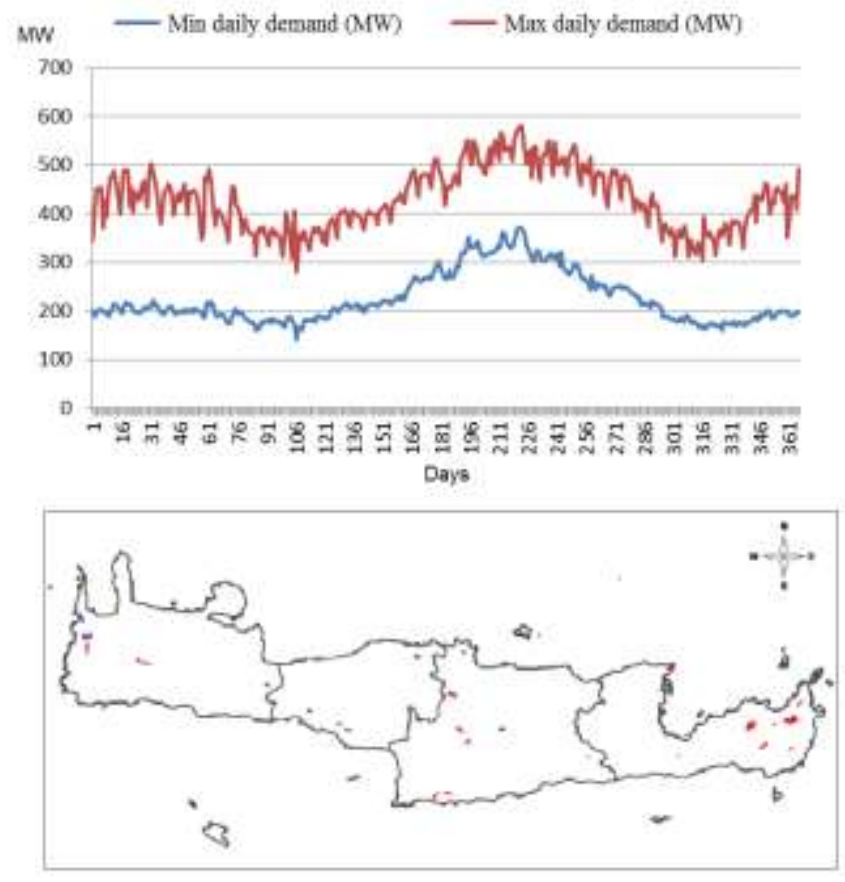

Fig. 2 Wind parks of Crete's Island

Currently, there are thirty four (34) wind parks, mostly in the eastern part of the island, of $184.6 \mathrm{MW}$, representing the $23 \%$ of the total installed power. The corresponding wind parks allocation is depicted in Fig. 2.

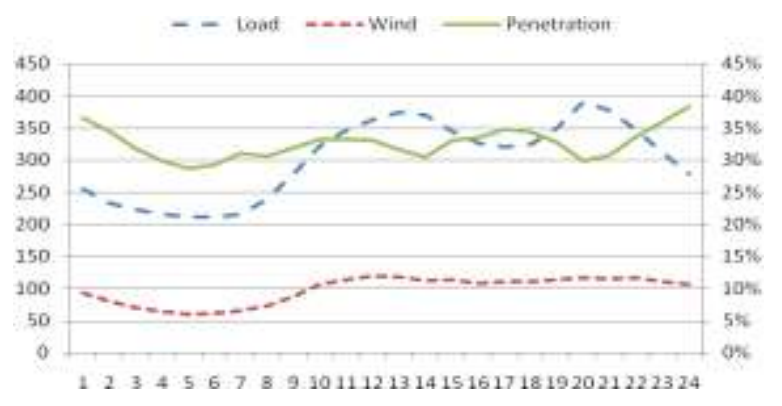

Fig. 3 Daily generation (MW)

According to data of 2014, the contribution of wind farms to the production system fluctuated on a monthly basis from $13 \%$ to $24 \%$ or in absolute terms from 30 to 
60GWh, while the total annual production reached 500GWh.

In particular, Fig. 3 shows that there is a clear decrement of wind power during night hours, incommensurate compared to wind velocity, due to low load demand at these hours and the conventional units' technical minimum. Thus, in the previous specific case, there is a loss of wind energy approximately equal to $39 \mathrm{GWh}, 1.3 \%$ of the corresponding energy balance.

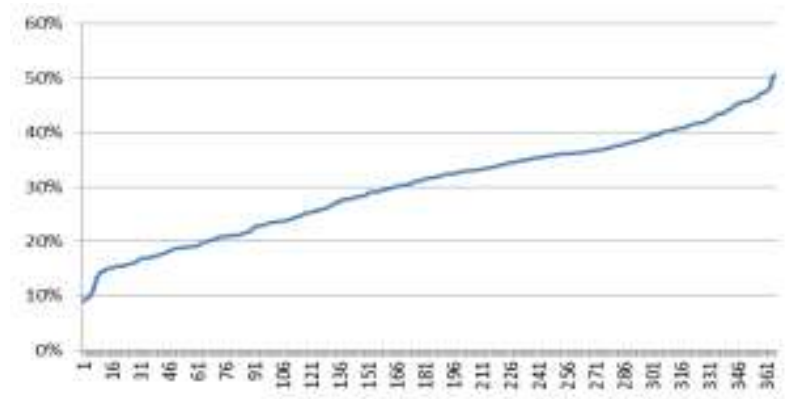

Fig. 4 Annual wind power penetration distribution

Next, Fig. 4 shows the distribution of daily maximum penetration rates for the year 2014 that vary from 10 to $50 \%$.

Since the beginning of 2010, 1200 small PV plants, $80 \mathrm{~kW}$ each, have been installed and operated to date, with $78 \mathrm{MW}$ in total.

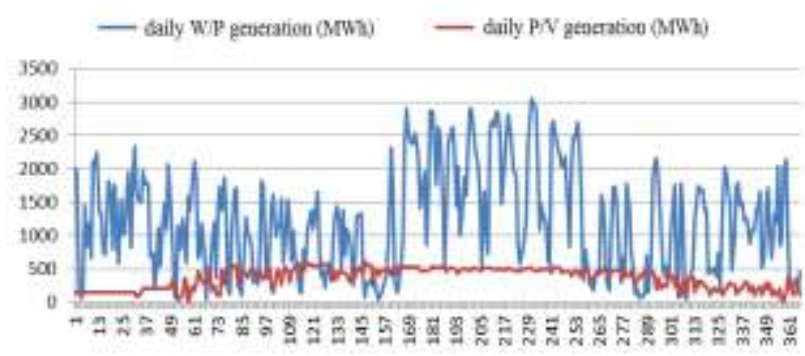

Fig. 5 WP and PV daily generation

According to recorded data by system operator, the contribution of PV units in the production system of Crete's power system ranged from 10 to $600 \mathrm{MWh}$, while the total annual production reached $123 \mathrm{GWh}$. More precisely, the maximum daily generation occurred on $26^{\text {th }}$ of May, with a total of $606.5 \mathrm{MWh}$ and a maximum power output equal to $69.6 \mathrm{MW}$.

Furthermore, in Fig. 5 both the daily wind power, and the corresponding PVs generation for the year 2014 are depicted, with dispersion percentage of $63 \%$ and $42 \%$, respectively.

Fig. 6 shows the corresponding share of wind and solar power in the island's energy balance. In this case, small scale RES installations are not included due to lack of procedures for monitoring or supervising. These installations contribute only to the load demand decrement.

The annual energy consumption in Crete for 2013 was slightly over 3 TWh. Till 2009, the annual increase of electricity consumption was significant high, varying between $4 \%$ and $6 \%$. But during the previous years due to economic issues the corresponding rate has significantly decreased.

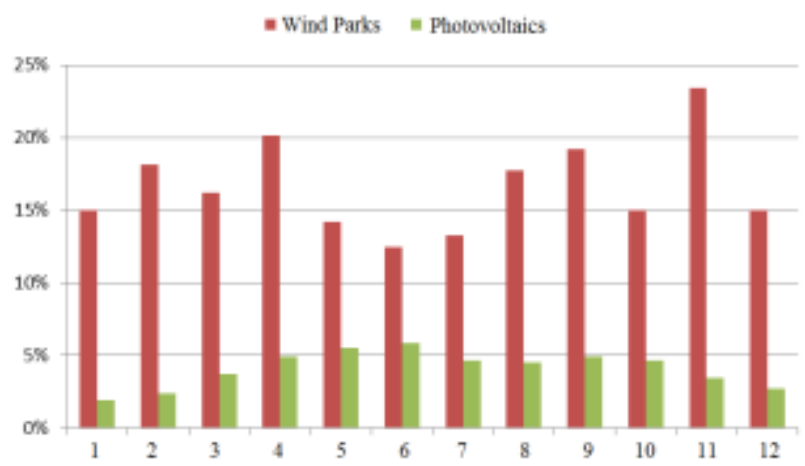

Fig. 6 WP and PV energy share per month

Thus, previous annual electricity demand evolution up to year 2020 has been re-estimated. The current estimation has taken into account both the corresponding population growth, the financial crisis and the energy saving that might be achieved (EU directive 2006/32) at Crete till 2020. In parallel, existing licenses approval will lead shortly to even higher wind power installation equal to $258 \mathrm{MW}$ in the near future, as it is shown in Table 1.

Due to, Greek Legislation (L.3468/2006) that promotes electricity production from RES, a boom of PV plants integration in Crete power system has been recorded. This fact led to even higher RES generation and wider power dispersal.

Thus, power system of Crete presents a representative model of island system for long term energy planning

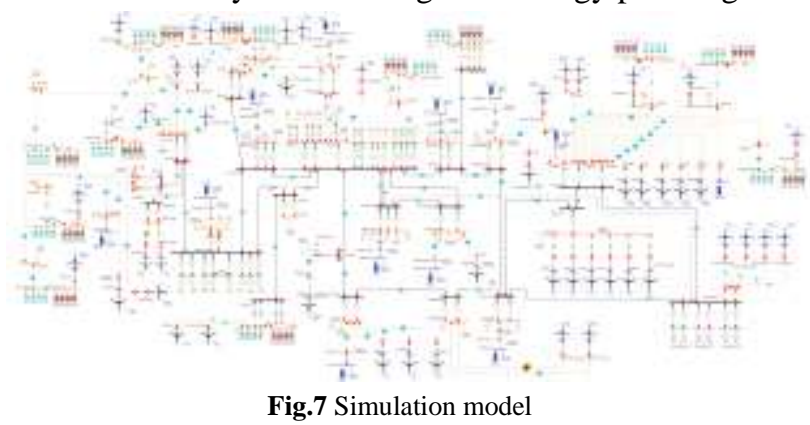

estimation, due to significant high share of RES and its expected future prospects. More precisely, in this study 
two basic assumptions (both separated and combined) have been investigated concerning previous mentioned further wind power utilization. The first case assumes pump energy storage systems operation of approximately $250 \mathrm{MW}$ installed power (hydro generation power) in Crete [12] that will allow further expansion of wind power. The second case assumes the interconnection of the island using the so far proposed technologies.

\section{Pump Storage Units Simulation}

An analytical model of the examined power system has been implemented in PowerWorld Simulator as it is presented in Fig. 7 for the simulation of the transient operation of the examined power system, under several operating conditions. Future scenarios of even higher RES penetration with the contribution of pump storage units as it is shown in Fig. 8 are included in this final model.

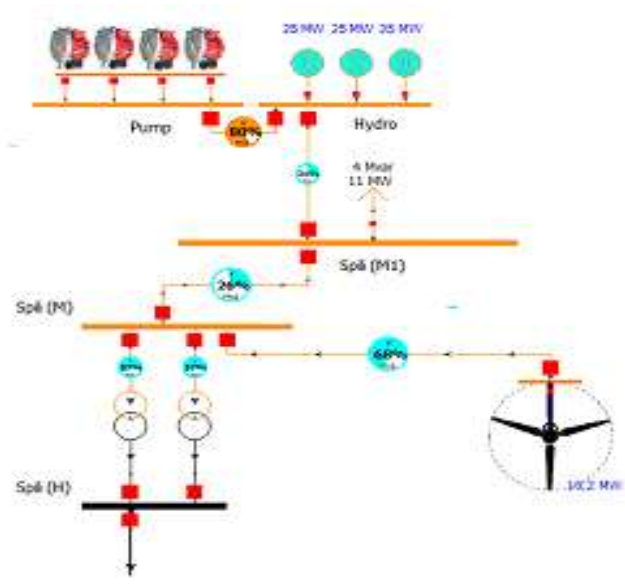

Fig. 8 One of the PSU that is about to be installed

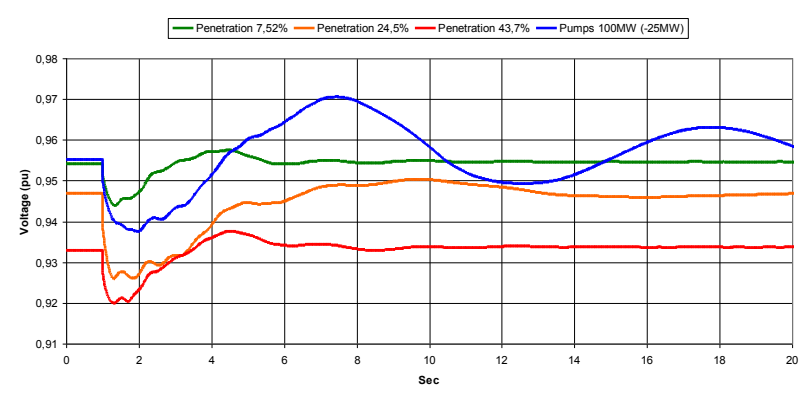

Fig. 9 Voltage variations

In this case energy storage system consists of pump storage units (PSUs) which are considered in operation with nominal power up to $100 \mathrm{MW}$. These units are used both as pumps and as hydro generator contributing to the operation planning and control of the examined power system.
Extensive transient analysis studies are conducted in order to assess the dynamic behavior of the system under various disturbances. In case of significant and sudden wind power variability voltage and frequency variations are recorded. In Fig. 9 the variation of voltage at the main wind park substation, are shown. The frequency follows the wind power changes, while the voltage profile follows an opposite trend. It can be easily seen that in case of ultra-high penetration of RES the power system remains satisfactorily stable if PSUs are in operation.

In Fig. 10 the frequency change in five different scenarios under the same disturbance is depicted. More precisely, the first three scenarios correspond to the three levels of RES penetration: (a) $7.5 \%$, (b) $24.5 \%$ and (c) $43.7 \%$. While in the next two scenarios the pump storage units are considered to operate (d) as hydro generators in their technical minimum and (e) as pumps that consume exclusively wind energy. The frequency behavior and the dynamic performance in general of the examined power system are clearly improved by the use of PSUs.

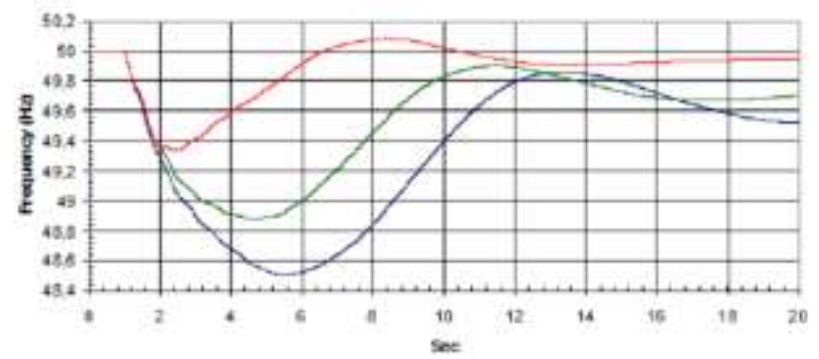

Fig. 10 Frequency fluctuations in different operation scenarios

Especially in case of PSUs operation as pumps the use of controlled load shedding enforce significant system stability.

\section{Conclusion}

The objective of this paper was to investigate and analyze the dynamic performance of a representative island system as power system of Crete with the assumption of even higher wind and PV power penetration levels. Review of several studies and corresponding results indicate that the re-dispatch strategy has an important impact on the transfer margin of a system, although it has an upper limit of contribution. It is well known that wind turbines and PVs are nondispatchable power sources with different operational characteristics than conventional power units. Thus, high levels of such power sources generation create issues of grid control, making percentage of PES penetration one of the most crucial parameters for the system stability. 
In this study several simulations have been performed to investigate the stability of the power system with high percentage of RES power penetration (up to $45 \%$ ). More precisely, frequent and significant disturbances of the system as short circuit, sudden disconnection of conventional power units as well as wind parks and strong wind velocity fluctuations have been simulated. As a second step the parallel operation of pump storage units have been analyzed in order to assess the level of their contribution to dynamic performance of the system. Results have shown that the deviations of the power system voltage and frequency remain acceptable under many examined perturbations without PSUs. However, the situation depends on the scheduling of the power units and the amount of allocated spinning reserve. In contrary the system remained stable in all the examined cases when PSUs have been considered in operation.

Concluding although installation of a large amount of RES (mainly WTs and PVs) in an island such as Crete affect significant the transient stability of the power system, they should not considered as a principal and a main obstacle to an adequate secure and reliable operation. The stability of a power system can be maintained even if high penetration of wind and solar power exist by additional system measures, control enhancement, preventive actions and even more with energy storage systems. It is a fact that these issues of both additional system measures and energy storage systems are particularly important for the dynamic performance of the system; therefore their contribution should be further investigated and their exact benefits to be clarified.

\section{References}

[1] A. Gigantidou. "Renewable energy sources in Crete", in Bulk Power System Dynamics and Control-IX Optimization, Security and Control of the Emerging Power Grid (IREP Symposium 2013), pp. 1-3, (2013,

[2] J. Stefanakis. "Crete: An ideal case study for increased wind power penetration in medium sized autonomous power systems", in Proc. IEEE Power Engineering Society (PES) Winter Meeting, pp. 329-334, (2002).

[3] N. Hatziargyriou, G. Contaxis, M. Matos, J. P. Lopes, G. Kariniotakis, D. Mayer, A. P. Figueira. "Energy management and control of island power systems with increased penetration from renewable sources", in Proc. IEEE Power Engineering Society (PES) Winter Meeting, pp. 335-339, (2002).
[4] Papathanasiou; S., Boulaxis, N., (2006). Power limitations and energy yield calculation for wind farms operating in island systems, Elsevier, Renewable Energy, 31, (4), pp. 457-479.

[5] Giatrakos, G.P., Tsoutsos, T.D., Zografakis, N., 2009. "Sustainable power planning for the island of Crete". Energy Policy 37 (4), pp. 1222-1238.

[6] Kaldellis, J., Kavadias, A., Filios, A., Garofalakis, S., 2004. "Income loss due to wind energy rejected by the Crete island electrical network: the present situation”. Applied Energy 79, pp. 127-144.

[7] Kaldellis, J.K., Kavadias, K.A., Filios, A.E, 2009. "A new computational algorithm for the calculation of maximum wind energy penetration in autonomous electrical generation systems". Applied Energy 86 (7-8), pp. 1011-1023.

[8] Karapidakis, E.S., Thalassinakis, M., 2006. “Analysis of Wind Energy Effects in Crete's Island Power System". 6th International World Energy System Conference, Turin, Italy, July 2006.

[9] Tsoutsos, T., Drandaki, M., Frantzeskaki, N., Iosifidis, E., Kiosses, I., 2009. "Sustainable energy planning by using multi-criteria analysis application in the island of Crete". Energy Policy, 37, pp. 15871600 .

[10] Kundur, Prabha, Paserba John, Ajjarapu Venkat, Andersson Göran, Bose Anjan, Canizares Claudio, Hatziargyriou Nikos, Hill David, Stankovic Alex, Taylor Carson, Thierry Van Cutsem, and Vittal Vijay 2004. "Definition and Classification of Power System Stability". IEEE Transactions on Power Systems, Vol. 19, No. 2, May 2004, pp.1387-1401.

[11] Smith, P., O’Malley, M., Mullane, A., Bryans, L., Nedic, D. P., Bell, K., Meibom, P., Barth, R., Hasche, B., Brand, H., Swider, D. J., Burges, K., Nabe, C., 2006. "Technical and Economic Impact of High Penetration of Renewables in an Island Power System". CIGRE Session 2006, Paper C6-102.

[12] Katsaprakakis, D., Christakis, D., Zervos, A., Papantonis, D. Voutsinas, S,. 2008. "Pumped storage systems introduction in isolated power production systems". Renewable Energy 33, pp. 467-490.

[13] Zografakis, N., 2005. “CRETE: A preferential island for extensive applications of renewable energy sources in Europe and Mediterranean," International Conference on Renewable Energy for Islands, Brussels, 21 September. 
E. S. Karapidakis
Hydro Pump Storage Energy Units in Crete's Power System

[14] Tsioliaridou, E., Bakos, G.C., Stadler, M., 2006. “A electricity sector-application for the island of new energy planning methodology for the Crete”. Energy Policy, 34, pp. 3757-3764. 